\title{
Mobility of tropical tunas and the implications for fisheries management
}

\author{
John Sibert $^{\mathrm{a}, *}$, John Hampton ${ }^{\mathrm{b}}$ \\ ${ }^{a}$ Pelagic Fisheries Research Program, Joint Institute of Marine and Atmospheric Research, School of Ocean and Earth Sciences \& Technology, \\ University of Hawaii, 1000 Pope Road, MSB 313, Honolulu, Hawaii 96822, USA \\ ${ }^{\mathrm{b}}$ Oceanic Fisheries Program, Secretariat of the Pacific Community, B.P. D5, 98848 Noumea Cedex, New Caledonia
}

Received 15 April 2002; accepted 1 October 2002

\begin{abstract}
We apply an advection-diffusion reaction model to data from three different tuna tagging experiments in the western and central Pacific Ocean (WCPO) to reexamine the question of to what extent the population dynamics and spatial characteristics of tropical tunas require international cooperation for effective management. The median lifetime displacement of skipjack ranges from 420 to 470 nautical miles. The lifetime displacement of yellowfin is about $20 \%$ less. The median half-life, a measure of residence time, of skipjack and yellowfin in WCPO exclusive economic zones (EEZs) is 3-6 months. Fishing decreases the lifetime displacement and decreases the half-life. We conclude that international arrangements between neighboring EEZs are essential for effective conservation, but that Pacific Island countries can achieve benefits from domestic conservation and fishery development policies.

(C) 2002 Elsevier Science Ltd. All rights reserved.
\end{abstract}

Keywords: Tuna fishery management; Diffusion models; Movement; Mortality

\section{Introduction}

Hilborn and Sibert [1] challenged the conventional view, as enshrined in the United Nations Convention on the Law of the Sea, that skipjack tuna (Katsuwonus pelamis) and yellowfin tuna (Thunnus albacares) are highly migratory. They based their argument mainly on the observation that most tag recaptures show displacements of less than about 200 nautical miles, with very few exhibiting the long-distance movements for which tuna are renowned. They further argued that restricted movement, in combination with high natural mortality rates and large exclusive economic zones (EEZs), substantially weakens the need for international cooperation in fishery management. Hilborn and Sibert maintained that this was particularly so for skipjack and yellowfin tuna fisheries, for which the bionomic equilibrium stock sizes are likely to be relatively high.

*Corresponding author. Tel.: + 1-808-956-4109; fax: + 1-808-9564104.

E-mail addresses: jsibert@soest.hawaii.edu (J. Sibert), johnh@spc.int (J. Hampton).
Responses to Hilborn and Sibert's paper [2,3] noted several problems in the interpretation of the tagging data, particularly the South Pacific Commission's $\left(\mathrm{SPC}^{1}\right)$ Skipjack Survey and Assessment Programme (SSAP) data. These concerns can be summarized as follows:

- Tagged tuna are typically caught in greatest numbers soon after release, before there has been time to move long distances. This biases simplistic representations of movement probabilities based on tag recapture data towards shorter movements.

- At the time of the SSAP, pole-and-line fishing predominated in the western Pacific, and effort was concentrated in the vicinity of islands where live bait supplies were most plentiful. Tag releases were also concentrated in these areas for the same reason (poleand-line vessels were used to capture tuna for tagging). These patchy distributions of fishing effort and tag releases may have biased observed recaptures towards fish that never left the release area, while fish that did leave the area would have had a much reduced chance of observation.

\footnotetext{
${ }^{1}$ Now known as the Secretariat of the Pacific Community.
} 
- The estimates of natural mortality rate used by Hilborn and Sibert were actually total attrition rates, and as such would have included an unknown component of movement into unfished areas.

- Variable reporting of recaptured tags may have further biased the recapture data towards shorter movements and times at liberty.

These problems in the interpretation of the SSAP tagging data were due largely to the lack of a model with which to estimate movement and mortality rates taking account of the distribution of tag releases and the distribution and variability of fishing effort. A spatial model of tagged tuna dynamics that satisfies these requirements has now been developed [4]. In this paper, we apply such a model to the SSAP tagging data and to more recent SPC tagging data for both skipjack and yellowfin tuna to shed light on the two key questions originally posed by Hilborn and Sibert:

- Are skipjack and yellowfin tuna highly migratory?

- Do their population dynamics and the spatial characteristics of the fisheries in the western Pacific require international cooperation for effective management?

Re-examination of these questions is now particularly timely. The 1995 Agreement for the Implementation of the United Nations Convention of the Law of the Sea of 10 December 1982 relating to the Conservation and Management of Straddling Fish Stocks and Highly Migratory Fish Stocks (commonly known as the Fish Stocks Agreement) [5] has prompted coastal states and fishing nations involved in the tuna fishery in the western and central Pacific Ocean (WCPO) to develop a new convention for the conservation and management of regional tuna stocks [6]. A new commission is expected to be established when the convention enters into force. The impact of tuna movement and other aspects of their population dynamics on the effectiveness of different management approaches will be important questions for the commission to consider. Also, there have been substantial changes in the WCPO tuna fishery since the SSAP was undertaken. The surface fishery has evolved from primarily a skipjack pole-and-line fishery to a purse seine fishery targeting both skipjack and yellowfin tuna (Fig. 1). Annual catches of skipjack have increased from about $400,000 \mathrm{t}$ in the early 1980 s to in excess of $900,000 \mathrm{t}$ in the 1990s [7]. During the same period, yellowfin catches have increased from around 200,000 to $450,000 \mathrm{t}$. Catches are no longer concentrated in the vicinity of islands but are more broadly distributed across the equatorial waters of the WCPO (Fig. 1). This recent period of higher catches coincided with SPC's Regional Tuna Tagging Project (RTTP), in which large numbers of skipjack and yellowfin were tagged throughout the western tropical Pacific during 1989-1992 [8]. This experiment, in which detailed complementary data on tag reporting rates were also collected [9], provides a unique opportunity to reevaluate tuna movement characteristics under experimental conditions very different to those that prevailed during the SSAP.

\section{Estimation of skipjack and yellowfin tuna movement and mortality}

We use a spatially explicit advection-diffusion reaction model [4] to estimate the movement and mortality of tagged tuna. Movement is parameterized in the model as a combination of region- and season-specific diffusive (random) and advective (directed) components. The movement process may be thought of as being the population equivalent of individual movement based on a biased random walk. The population dynamics are computed on a one-degree-square spatial grid and monthly time step, but the model is parameterized by assuming that movement parameters are homogeneous within specified geographical regions and seasons, fishing mortality is proportional to fishing effort, and the natural mortality rate is constant over area and time.

The general model structure is completely defined in [4], however its application to the RTTP data required several modifications. The model domain and definition of regions are shown in Fig. 2. Tag releases were stratified into monthly cohorts, that is, all of the tagged fish released during 1 month were distributed at their points of release in the model domain, and the movement and mortality of each cohort was followed for a period of 36 months. Time and place of fishing for the domestic fleets of the Philippines and Indonesia are not recorded, but the model requires fishing effort by month and one degree geographic square. Fishing effort for these two fleets was arbitrarily set to 1.0 in those $1^{\circ} \times 1^{\circ} \times$ month strata where tags were recaptured and to zero elsewhere. A negative binomial likelihood function [10] was employed that allows estimation of a parameter for each fleet describing the variance of the relationship between fishing effort and tag returns. Fishing effort was "normalized" to the mean over the strata in which each fleet operated allowing estimates of catchability to be rescaled to estimates of average fishing mortality for each fleet over the whole model domain.

We applied the model to three sets of tagging data(i) the same SSAP skipjack tuna data analyzed by Hilborn and Sibert, which cover a period from October 1977 to August 1983; (ii) the RTTP skipjack tuna data, which cover a period from July 1989 to December 1995; and (iii) the RTTP yellowfin tuna data, which cover the same period as RTTP skipjack tuna. 


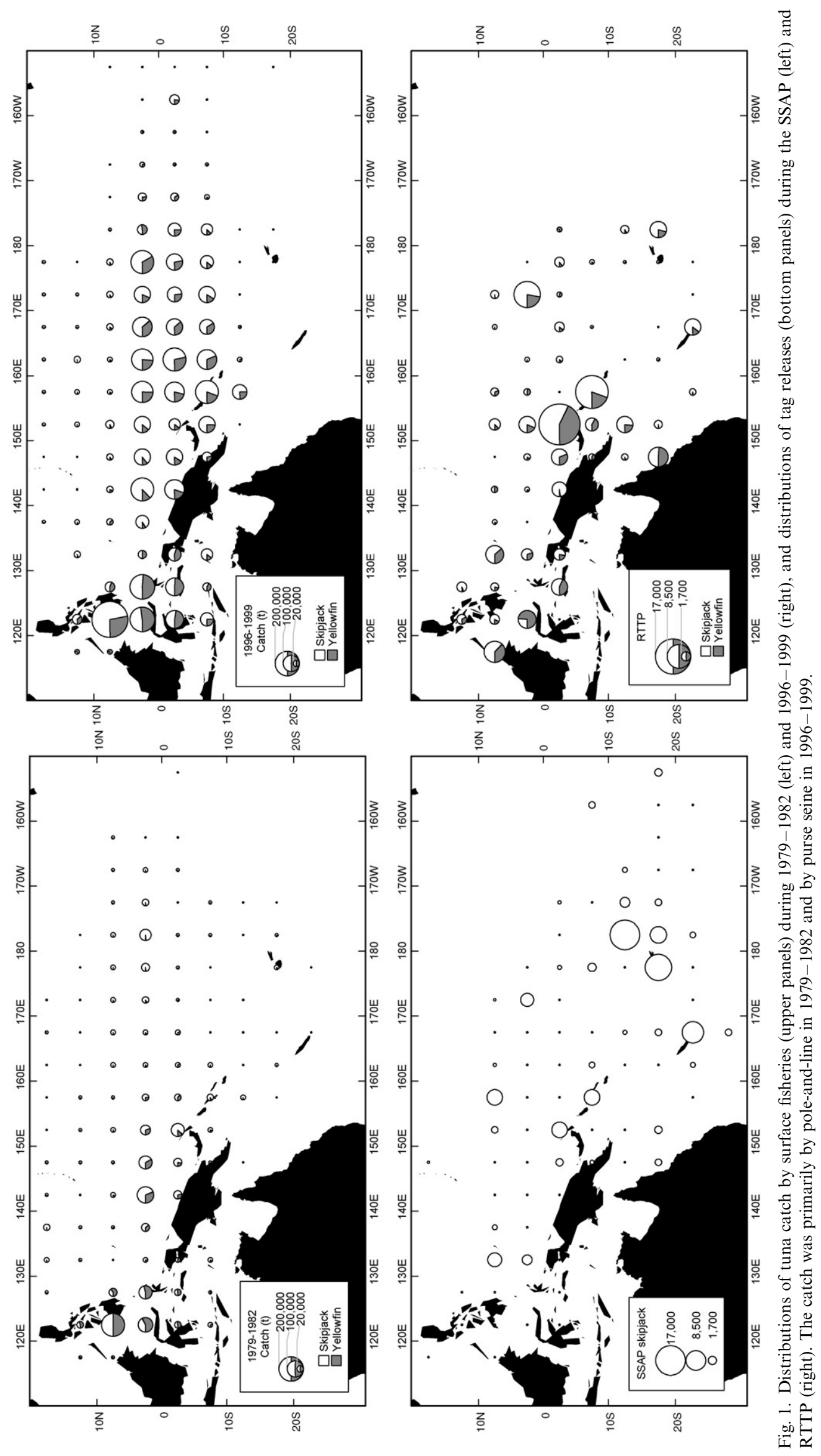




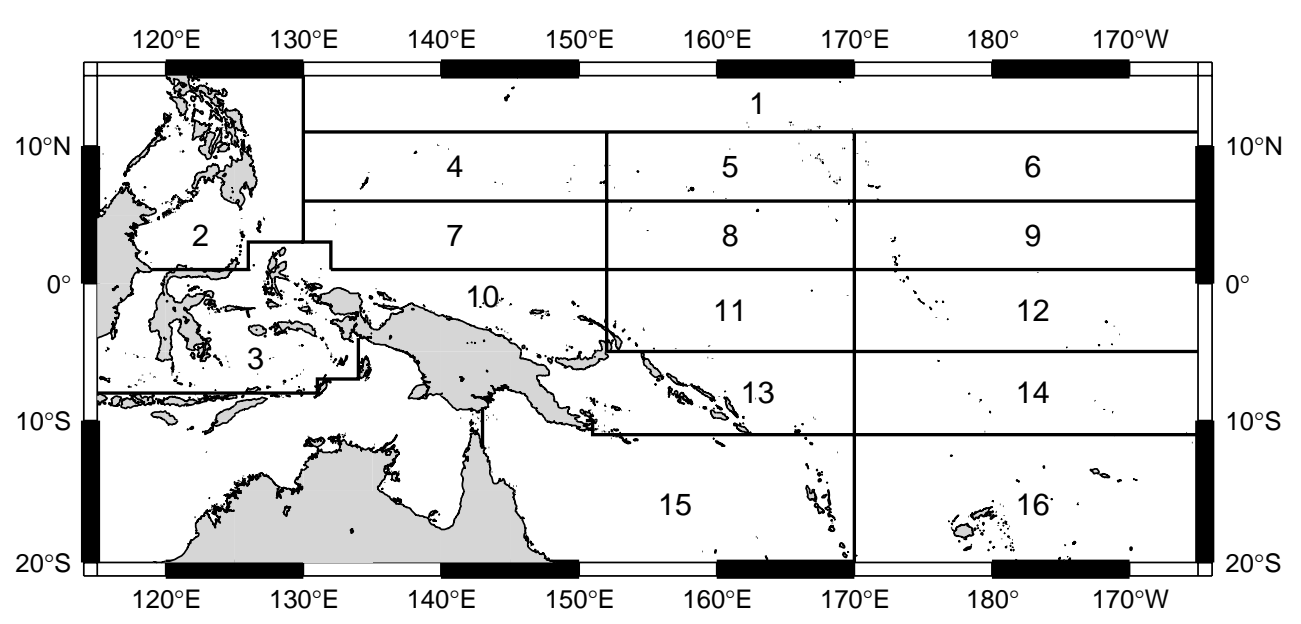

Fig. 2. Model domain and the 16 regions used in the spatial model.

For the RTTP analyses, estimates of tag-reporting rates by the various fleets were incorporated into the model as fixed parameters [9]. For the SSAP, independent estimates of tag-reporting rates were not available; therefore, the fishing mortality estimates for this analysis may be underestimated due to incomplete tag reporting.

The RTTP tagging experiment included large numbers of releases of relatively small-sized tuna in the Philippines. As natural mortality is strongly sizedependent [11], natural mortality rates for the Philippines region were estimated as separate parameters for the RTTP analyses.

\subsection{Mortality and exploitation}

Table 1 shows the estimated natural mortality and fishing mortality rates for the three data sets. Average fishing mortality rate was computed by multiplying the estimated catchability coefficients by the proportion of the total fished area exploited by each fleet.

The natural mortality rate for skipjack in both the SSAP and RTTP and for yellowfin in the RTTP is approximately $0.11-0.12$ month $^{-1}$. The skipjack natural mortality rate estimates are remarkably consistent in light of the changes in exploitation that occurred between the SSAP and RTTP time periods. The skipjack natural mortality rate estimates reported here are very similar to those estimated previously using a different model domain and fishing mortality parameterization [4]. The natural mortality rate for yellowfin in the Philippines is slightly higher than that in the remainder of the model domain, reflecting the high proportion of juveniles tagged there. The changes in average skipjack fishing mortality between the SSAP and RTTP period reflect the shift from pole-and-line to purse seine fishing and the general increase in
Table 1

Estimates of natural and fishing mortality (per month)

\begin{tabular}{llll}
\hline & SSAP & RTTP & \\
\cline { 3 - 4 } & & Skipjack & Yellowfin \\
\hline Area (natural mortality) & 0.111 & 0.118 & 0.108 \\
$\quad$ Region & & & 0.128 \\
$\quad$ Philippines & & & \\
Fleet (fishing mortality) & 0.00175 & & \\
$\quad$ Papua New Guinea P\&L & 0.00027 & 0.00057 & 0.00024 \\
Fiji P\&L & 0.00441 & 0.00356 & \\
Japan P\&L & & 0.00005 & \\
Kiribati P\&L & 0.00133 & 0.00210 & 0.00027 \\
$\quad$ Solomon Islands P\&L & 0.00094 & 0.01489 & 0.01478 \\
Japan PS & & 0.02505 & 0.01569 \\
$\quad$ Korea PS & & 0.00237 & 0.00192 \\
$\quad$ Philippines PS & & 0.00136 & 0.00188 \\
$\quad$ Solomon Islands PS & & 0.01130 & 0.01044 \\
$\quad$ Taiwan PS & & 0.01106 & 0.01052 \\
$\quad$ United States PS & & 0.00046 & 0.00157 \\
$\quad$ Indonesia (domestic) & & 0.00181 & 0.00249 \\
$\quad$ Philippines (domestic) & & & \\
Total fishing mortality & 0.00870 & 0.07459 & 0.05982 \\
Total mortality & 0.120 & 0.192 & 0.168 \\
\hline
\end{tabular}

The estimate of skipjack natural mortality in the Philippines is not significantly different from the regional estimate $(P<0.001)$; the estimate of yellowfin natural mortality in the Philippines is different from the regional estimate with $P=0.81$ (likelihood ratio test). $\mathrm{P} \& \mathrm{~L}$ indicates pole and line fishing PS indicates purse seine fishing. The Philippines and Indonesia domestic fleets consist of a variety of smallscale fishing methods, including handline, troll and gillnet.

total harvest. The sum of the natural and fishing mortality rates for the SSAP is 0.12 month $^{-1}$, lower than the previously estimated total mortality rate of $0.17 \mathrm{month}^{-1}$ obtained using a spatially aggregated model [12]. This difference probably reflects the contribution of emigration from the fishing grounds, a factor not estimated in the aggregated analysis, to the estimate of total attrition. 


\subsection{Movement}

For our purposes, the net distance moved (displacement) over the lifetime of the fish is a more useful measure of mobility than the numerical values of the estimated movement model parameters. Hilborn and Sibert interpreted the raw tag-return data for the SSAP in this way. However, their interpretation was almost certainly biased by the effects of the distribution of tag releases in relation to the distribution of fishing effort [3]. Using the spatial model, it is possible to compute lifetime displacement probabilities that are, in essence, corrected for the effects of the distributions of tags releases and fishing effort. Such displacement probabilities also incorporate the effect of natural mortality as this "process" is an integral component of the model. In other words, the modeled displacements should better represent the intrinsic movement and mortality characteristics of the fish and not be biased by the experimental design.

The distribution of observed displacements for all tags recaptured in both experiments is shown in Fig. 3. Most
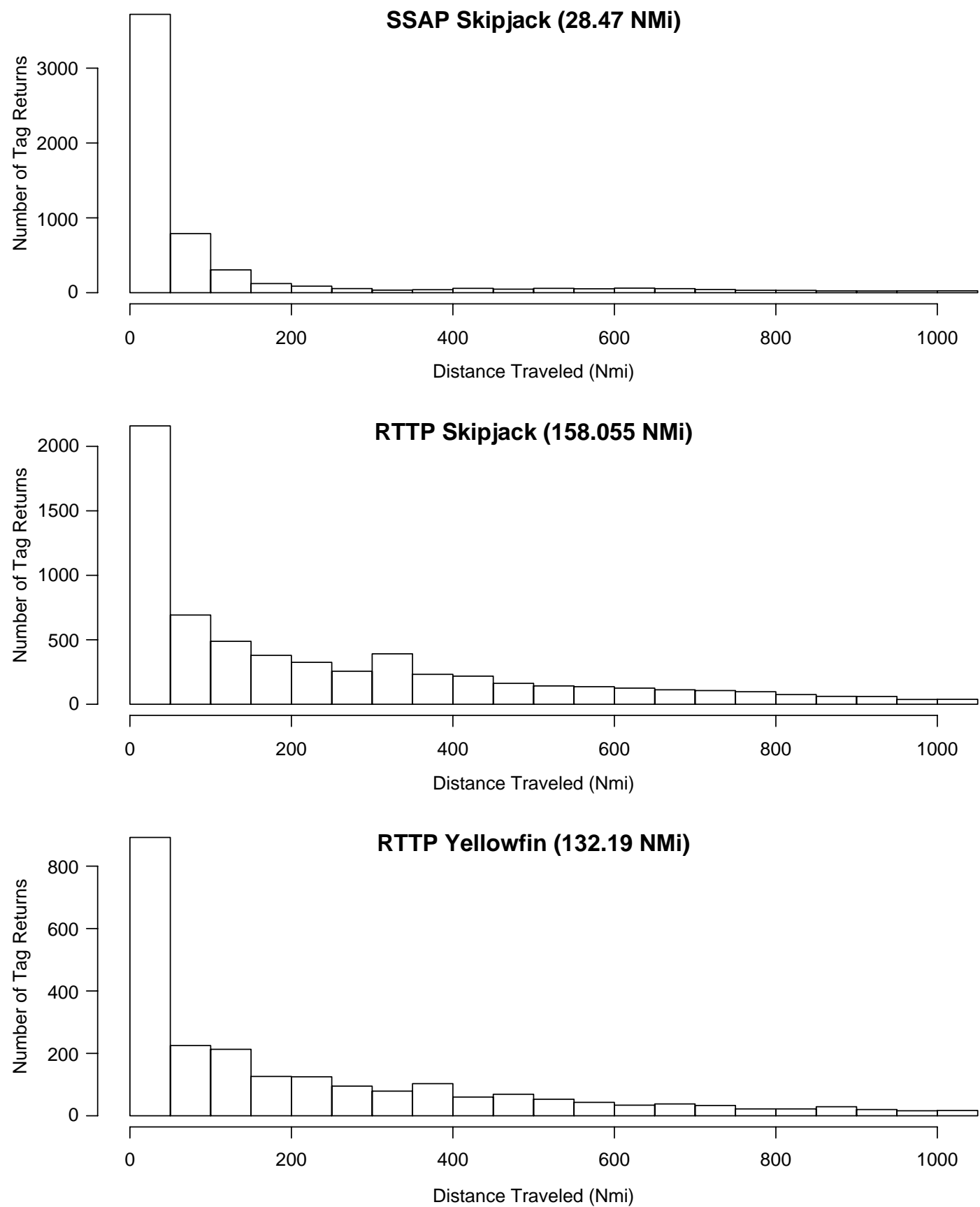

Fig. 3. Distributions of observed tag displacements for the three data sets. The median displacement in each case is shown in parentheses. 


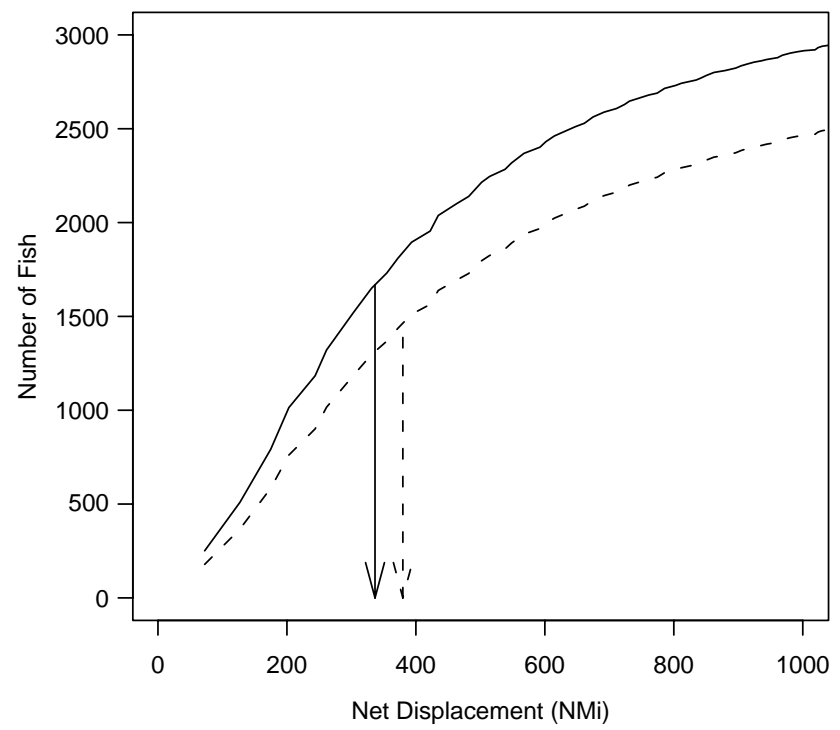

Fig. 4. Modeled cumulative distribution of displacements of yellowfin tuna tagged during the RTTP with (solid lines) and without (dashed lines) fishing mortality. The arrows indicate the displacement exceeded by half of the tagged population (median displacement).

skipjack tags returned in the SSAP were recaptured within 200 miles of the point of release and the median displacement was only 28 nautical miles. Both skipjack and yellowfin returned during the RTTP appear to have moved farther with median displacements of 158 and 132 nautical miles, respectively. These differences may reflect the large numbers of tags released and recaptured on active pole-and-line fishing grounds during the SSAP.

We calculated the displacements from the points of release of all tagged fish in the model domain during their lifetime. We also computed the median displacement as the displacement exceeded by $50 \%$ of the fish during their lifetime. These calculations are illustrated graphically in Fig. 4 for RTTP tagged yellowfin. Numerical estimates of median displacement for the three data sets are presented in Table 2. Skipjack have a median lifetime displacement ranging from 420 to 470 nautical miles, an estimate which is consistent between the SSAP and RTTP experiments. The median lifetime displacement of yellowfin is about $20 \%$ less than that of skipjack. Fishing has the expected effect of reducing the lifetime displacement. These model-based estimates are about twice those of the empirical estimates obtained from the tag recaptures alone (Fig. 3).

By definition, only $50 \%$ of the fish move beyond the median displacement distance. The remainder apparently persist in an area closer to the place where they were tagged. The spatial model can also be used to compute the amount of time it would take for the population to decrease by half, the "half-life", in an arbitrary area assuming a uniform distribution of fish in the model domain. Estimates of half-life by EEZ are
Table 2

Median displacements in nautical miles for tagged fish computed from the spatial model using actual tag releases

\begin{tabular}{lll}
\hline & With fishing & Without fishing \\
\hline SSAP skipjack & 419 & 424 \\
RTTP skipjack & 411 & 471 \\
RTTP yellowfin & 337 & 380 \\
\hline
\end{tabular}

shown in Table 3. The EEZ boundaries used to compute these half-life estimates are shown in Fig. 5. Although the half-life in some EEZs is as low as 3 months, the median half-life over all EEZs is approximately 6 months. Fishing has the effect of decreasing half-life. The change in exploitation between the SSAP and RTTP periods can be clearly seen by comparing the median half-life with and without fishing.

\section{Management implications}

As pointed out by Hilborn and Sibert [1], the success of international management arrangements depends on whether policies have a sound foundation in economics, politics and biology. The biological characteristics of tropical skipjack and yellowfin tunas estimated in this study are such that their movements will carry a significant proportion of the population beyond most EEZs during their lifetime. Some degree of cooperation between neighboring states would, therefore, appear to be essential for conservation and optimal exploitation of skipjack and yellowfin stocks.

Half-life estimates indicate that substantial proportions of the population reside for periods of approximately 6 months within the EEZs of Pacific Island States. Given the high growth rates of these species [13-15], this period of time is potentially sufficient to produce a significant proportion of the total growth of the fish. A substantial proportion of the population production takes place within a single EEZ, particularly for skipjack in EEZs with half-lives greater than the median. Longer periods of residency provide the opportunity for implementation of effective unilateral domestic policies. It should be possible to base successful domestic fisheries on the expected yield from that portion of the population that persists within EEZs. By the same argument, island states should not completely depend on international arrangements for conservation. Domestic conservation policies are necessary and can be an effective component of national fishery development strategies.

The rather restricted displacement reported here, 400 500 nautical miles, suggests that sub-regional regimes could be considered rather than attempting to apply a uniform regime over the entire range of the stock. Thus, 
Table 3

Time in months for the population in each EEZ to be reduced by one half with ( $q$ Est) and without $(q=0)$ fishing

\begin{tabular}{|c|c|c|c|c|c|c|}
\hline & \multirow{3}{*}{$\begin{array}{l}\text { SSAP } \\
q \text { Est. }\end{array}$} & \multirow[b]{3}{*}{$q=0$} & \multicolumn{4}{|l|}{ RTTP } \\
\hline & & & \multicolumn{2}{|c|}{ Skipjack } & \multicolumn{2}{|c|}{ Yellowfin } \\
\hline & & & $q$ Est. & $q=0$ & $q$ Est. & $q=0$ \\
\hline \multicolumn{7}{|l|}{ EEZ name } \\
\hline American Samoa (ASM) & 9.8 & 10.0 & 7.7 & 8.3 & 6.0 & 6.1 \\
\hline Fiji (FIJ) & 7.5 & 7.8 & 4.2 & 4.6 & 5.8 & 6.2 \\
\hline Federated States of Micronesia (FSM) & 4.4 & 4.6 & 3.1 & 5.4 & 3.5 & 5.5 \\
\hline Gilbert Islands (KIR) & 6.0 & 6.7 & 5.3 & 8.6 & 6.7 & 10.3 \\
\hline Guam (GUM) & 5.7 & 5.8 & 6.4 & 7.3 & 4.1 & 4.5 \\
\hline Howland \& Baker Is. (HOW) & 9.2 & 9.8 & 7.3 & 9.9 & 9.1 & 12.5 \\
\hline Indonesia (ID) & 7.8 & 7.8 & 5.9 & 6.6 & 4.2 & 7.2 \\
\hline Marshall Islands (MAR) & 8.1 & 8.4 & 6.7 & 9.5 & 5.3 & 7.1 \\
\hline Nauru (NAU) & 6.2 & 6.3 & 3.4 & 6.2 & 5.4 & 8.7 \\
\hline New Caledonia (NC) & 4.8 & 4.9 & 3.6 & 3.6 & 7.0 & 7.1 \\
\hline Niue $(\mathrm{NI})$ & 14.3 & 15.1 & 6.7 & 6.7 & 5.0 & 5.1 \\
\hline Palau (PAL) & 4.0 & 4.1 & 2.2 & 3.9 & 2.2 & 3.4 \\
\hline Philippines (PH) & 6.5 & 6.5 & 3.0 & 6.5 & 2.6 & 5.5 \\
\hline Phoenix Islands (KIR) & 4.7 & 4.7 & 7.2 & 9.3 & 6.8 & 7.1 \\
\hline Papua New Guinea (PNG) & 4.8 & 5.4 & 4.3 & 6.5 & 4.2 & 8.2 \\
\hline Samoa (SAM) & 7.8 & 8.0 & 5.5 & 5.7 & 6.6 & 6.8 \\
\hline Solomon Islands (SOL) & 5.4 & 6.2 & 4.9 & 6.9 & 6.5 & 7.9 \\
\hline Tokelau (TOK) & 4.6 & 4.6 & 4.8 & 5.6 & 5.6 & 6.0 \\
\hline Tonga (TON) & 8.2 & 8.6 & 6.0 & 6.3 & 5.7 & 5.8 \\
\hline Tuvalu (TUV) & 5.4 & 5.5 & 4.3 & 5.4 & 5.9 & 6.9 \\
\hline Vanuatu (VAN) & 4.7 & 4.7 & 3.8 & 3.9 & 9.0 & 9.1 \\
\hline Wallis \& Futuna (WAL) & 7.4 & 7.6 & 4.5 & 4.9 & 6.5 & 6.8 \\
\hline Median EEZ half-life & 6.1 & 6.4 & 4.9 & 6.4 & 5.8 & 6.8 \\
\hline \multicolumn{7}{|l|}{ High seas areas } \\
\hline I61 & 4.7 & 5.3 & 1.9 & 5.1 & 2.5 & 5.5 \\
\hline $\mathrm{I} 62$ & 5.8 & 6.1 & 3.5 & 5.2 & 5.2 & 8.1 \\
\hline $\mathrm{I} 63$ & 7.8 & 8.2 & 6.3 & 9.0 & 7.6 & 10.4 \\
\hline
\end{tabular}

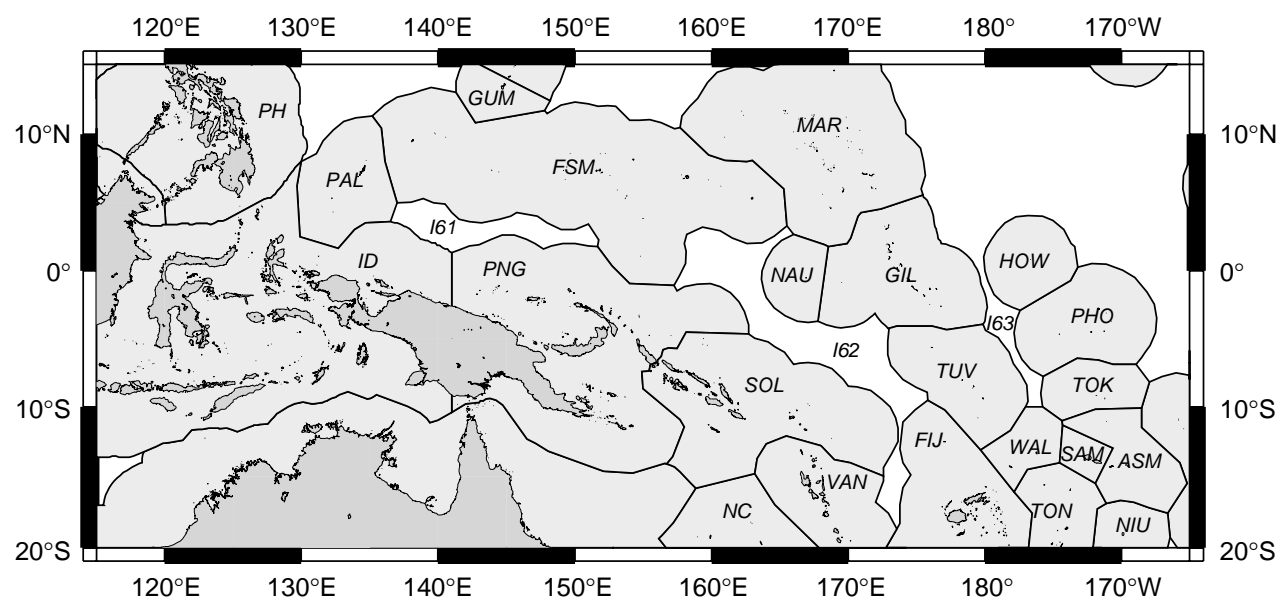

Fig. 5. Exclusive economic zones in spatial model. These boundaries are approximate and computations were carried out with a resolution of one geographic degree.

for example, one could call for a restriction in juvenile harvests of yellowfin in the equatorial FAD fishery and still allow such harvests in the much smaller handline fishery in Hawaii, several displacement diameters away.
In other words, allowing juvenile harvests in Hawaii would not undermine the intent of restricting such harvests along the equator. The Japanese offshore skipjack fishery is another example of a situation where 
sub-regional management regimes could be applied. This fishery operates in the temperate waters of the Kuroshio Current several displacement diameters from the equatorial purse seine fishery.

Approximately $20 \%$ of the WCPO tuna catch is taken in high-seas areas outside of any EEZ [16]. The high-seas populations exhibit the same median lifetime displacement as stocks within EEZs and high-seas regions have their own characteristic "residence times". Effective policies for conserving tunas obviously require agreement among nations that operate in the high-seas areas and among nations adjacent to these areas.

The WCPO contains isolated and semi-isolated highseas enclaves. The half-life of populations in high-seas enclave I61 between PNG and FSM is fairly low, approximately 2 months, and reflects a relatively high impact of fishing. The half-life in high-seas enclave I62 east of the Solomon Islands is somewhat longer. Eliminating fishing in these areas could potentially increase the half-life to approximately 6 months, near the regional median value, raising the possibility of designating the high-seas enclaves as conservation zones. The effectiveness of marine protected areas (MPAs) or other forms of maritime zoning for conserving tunas has never been demonstrated and is seldom even discussed. The model described in this paper could be used to assess the efficacy of MPAs as a conservation and management tool for tunas. This is a subject of further research.

\section{Conclusions}

The term, "highly migratory" appears to have no operational definition in relation to the natural history of tunas. Rather, it is a legal term defined only in the context of the Law of the Sea. If this term is ever to have any biological meaning, its definition should take into account relevant factors of the population dynamics of the species under consideration, such as the extent of movement in relation to mortality rates. The median lifetime displacement calculated here is one simple parameter that might be explored in relation to the designation "highly migratory". Whether median lifetime displacements on the order of 400-500 miles reported here for skipjack and yellowfin are sufficient to qualify these stocks as highly migratory is a question for further research.

The estimated movement and mortality characteristics of skipjack and yellowfin tuna suggest that fish are likely to be exposed to exploitation in more than one EEZ during their lifetime. This result means that international cooperation is required for effective conservation and management of these species. However, the results also suggest that Pacific Island countries can implement effective domestic management policies to promote conservation and sustainable utilization of tuna stocks within their EEZs. Such a composite and complementary approach to tuna fisheries management is well catered for in the Fish Stocks Agreement.

Regardless of the need for international cooperation in tuna fisheries management, the imperative for international cooperation in fisheries data collection and research is possibly even greater. The tagging experiments and the collection of fisheries data on which this paper depended are prime examples of the benefits of such cooperation. The experiments and their subsequent analysis could not have occurred without the cooperation of the coastal states and distant-water fishing nations of the WCPO.

\section{Acknowledgements}

The work described in this paper was sponsored in part by the University of Hawai'i Pelagic Fisheries Research Program under Cooperative Agreement number NA67RJ0154 from the National Oceanic and Atmospheric Administration. The views expressed here are those of the authors and do not necessarily reflect the positions of the Secretariat of the Pacific Community, the University of Hawai'i, NOAA, or any of its subagencies.

\section{References}

[1] Hilborn R, Sibert J. Is international management of tuna necessary. Marine Policy 1988;12(1):31-9.

[2] Mullen AJ. Mobility of tuna. Marine Policy 1989;13(1):77-8.

[3] Polacheck T. Another perspective on the need for international skipjack and yellowfin tuna management. Marine Policy 1990;14(11):526-9.

[4] Sibert JR, Hampton J, Fournier DA, Bills PJ. An advectiondiffusion reaction model for the estimation of fish movement parameters from tagging data, with application to skipjack tuna (Katsuwonus pelamis). Canadian Journal of Fisheries and Aquatic Sciences 1999;56:925-38.

[5] Lévy J, Schram GG. United Nations conference on straddling fish stocks and highly migratory fish stocks, selected documents. Martinus Nijhoff, The Hague, Netherlands, 1996.

[6] Convention on the conservation and management of highly migratory fish stocks in the western and central Pacific Ocean, www.ocean-affairs.com/convention.html

[7] Lawson TA, editor. Secretariat of the Pacific Community tuna fishery yearbook 1999. Secretariat of the Pacific Community, Noumea, New Caledonia, Lawson, 2000.

[8] Kaltongga B. Regional tuna tagging project: data summary. Technical Report No. 35, Oceanic Fisheries Programme, Secretariat of the Pacific Community, Noumea, New Caledonia, 1998.

[9] Hampton J. Estimates of tag-reporting and tag-shedding rates in a large-scale tuna tagging experiment in the western tropical Pacific Ocean. Fishery Bulletin, US 1997;95:68-79.

[10] Hampton J, Fournier DA. A spatially disaggregated, lengthbased, age-structured population model of yellowfin tuna (Thunnus albacares) in the western and central Pacific Ocean. Marine and Freshwater Research 2001;51:937-63. 
[11] Hampton J. Natural mortality rates in tropical tunas - size really does matter. Canadian Journal of Fisheries and Aquatic Sciences 2000;57:1002-10

[12] Kleiber P, Argue AW, Kearney RE. Assessment of Pacific skipjack tuna (Katsuwonus pelamis) resources by estimating standing stock and components of population turnover from tagging data. Canadian Journal of Fisheries and Aquatic Sciences 1987;44:1122-34.

[13] Wild A, Hampton J. A review of the biology and fisheries for skipjack tuna, Katsuwonus pelamiz, in the Pacific Ocean. In: Shomura R, Majkowski J, Langi S, editors. Interactions of pacific tuna fisheries: papers on biology and fisheries, vol. 2. FAO Fisheries Technical Paper 336/2, p. 1-51.
[14] Wild A. A review of the biology, fisheries for yellowin tuna, Thunnus albacares, in the eastern Pacific Ocean. In: Shomura R, Majkowski J, Langi S, editors. Interactions of pacific tuna fisheries: papers on biology and fisheries, vol. 2. FAO Fisheries Technical Paper 336/2, p. 52-107.

[15] Wild A. A review of the biology, fisheries for yellowin tuna (Thunnus albacares) in the western and central Pacific ocean. In: Shomura R, Majkowski J, Langi S, editors. Interactions of pacific tuna fisheries: papers on biology and fisheries, Vol. 2. FAO Fisheries Technical Paper 336/2, p. $108-137$.

[16] Secretariat of the Pacific Community, unpublished data. 